\title{
Mutation of the Cyba gene encoding p22 phox causes vestibular and immune defects in mice
}

\author{
Yoko Nakano, ${ }^{1,2,3}$ Chantal M. Longo-Guess, ${ }^{4}$ David E. Bergstrom, ${ }^{4}$ William M. Nauseef, ${ }^{2,3,5}$ \\ Sherri M. Jones, ${ }^{6}$ and Botond Bánfi $1,2,3$

\begin{abstract}
1Department of Anatomy and Cell Biology, 2Inflammation Program, and 3Department of Internal Medicine, University of lowa, lowa City, Iowa, USA. ${ }^{4}$ The Jackson Laboratory, Bar Harbor, Maine, USA. ${ }^{5}$ Department of Veterans Affairs, lowa City VA Medical Center, Iowa City, Iowa, USA. ${ }^{6}$ Department of Communication Sciences and Disorders, East Carolina University, Greenville, North Carolina, USA.
\end{abstract}

\begin{abstract}
In humans, hereditary inactivation of either $\mathrm{p}^{22^{p h o x}}$ or gp91 ${ }^{\text {phox }}$ leads to chronic granulomatous disease (CGD), a severe immune disorder characterized by the inability of phagocytes to produce bacteria-destroying ROS. Heterodimers of $\mathrm{p}^{22^{p h o x}}$ and gp91 ${ }^{\text {phox }}$ proteins constitute the superoxide-producing cytochrome core of the phagocyte NADPH oxidase. In this study, we identified the nmf333 mouse strain as what we believe to be the first animal model of $\mathrm{p}^{22^{p h o x}}$ deficiency. Characterization of $\mathrm{nmf333}$ mice revealed that deletion of $\mathrm{p}^{22^{\text {phox }}}$ inactivated not only the phagocyte NADPH oxidase, but also a second cytochrome in the inner ear epithelium. As a consequence, mice of the nmf333 strain exhibit a compound phenotype consisting of both a CGD-like immune defect and a balance disorder caused by the aberrant development of gravity-sensing organs. Thus, in addition

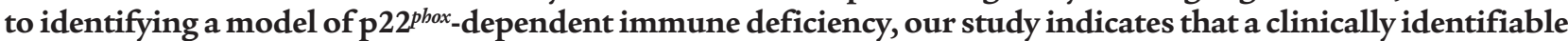
patient population with an otherwise cryptic loss of gravity-sensor function may exist. Thus, $\mathrm{p}^{22^{\text {phox }}}$ represents a shared and essential component of at least 2 superoxide-producing cytochromes with entirely different biological functions. The site of $\mathrm{p}^{22^{p h o x}}$ expression in the inner ear leads us to propose what we believe to be a novel mechanism for the control of vestibular organogenesis.
\end{abstract}

\section{Introduction}

The superoxide-producing NADPH oxidase (Nox) complex of phagocytes (Phox) is critical for the elimination of invading bacteria and fungi. The enzymatic core of Phox is a heterodimeric flavocytochrome composed of the transmembrane proteins gp9 $9 p^{\text {phox }}$ and $\mathrm{p} 22^{\text {phox }}$. Upon stimulation of phagocytes, the gp91 $1^{\text {phox }}$-p22 $2^{\text {phox }}$ dimer is activated by 3 additional subunits recruited from the cytosol: p47phox, p67phox, and Rac2 (or Rac1, depending on the myeloid lineage) (1). In the assembled oxidase complex, the flavocytochrome transports electrons from intracellular NADPH to extracellular or phagosomal oxygen (2). Superoxide is thus generated, and its derivatives - such as hydrogen peroxide and hypochlorous acid - are toxic to microbes. The importance of Phox to host defense is demonstrated by chronic granulomatous disease (CGD) - a hereditary disorder characterized by life-threatening infections and inflammatory granulomas (3). Although the immune defect develops when any 1 of the 5 Phox subunits is inactivated by mutation, gp $91^{\text {phox }}$ and $\mathrm{p} 47^{\text {phox }}$ deficiencies are the 2 most common forms of CGD. Mouse strains with targeted deletion of either of these 2 proteins recapitulate the known features of the human disease $(4,5)$. However, a lack of corresponding p22 $2^{\text {phox }}$ - and p67phox -deficient animal models has greatly limited the exploration of the less common types of CGD.

Recent studies have demonstrated that Phox is not the only enzyme with superoxide-producing function: $6 \mathrm{gp} 91^{\text {phox }}$ homologs have been discovered in humans and named Noxes or, when they contain both a gp91 phox-like and a peroxidase-like domain, dual

Nonstandard abbreviations used: CGD, chronic granulomatous disease; Duox, Dual oxidase; Nox, NADPH oxidase; Noxa1, Nox activator 1; Noxo1, Nox organizer 1; Phox, phagocyte Nox; VsEP, vestibular-evoked potential.

Conflict of interest: The authors have declared that no conflict of interest exists. Citation for this article: J. Clin. Invest. 118:1176-1185 (2008). doi:10.1172/JCI33835. oxidases (Duoxes) (6). The biological importance of most gp91phox (Nox2) homologs is not known, although some of the Nox/Duox proteins have been assigned a function. Duox 1 may participate in host defense activity in the airway epithelium $(7,8)$, and Duox2 plays a role in thyroid hormone synthesis (9). In vascular smooth muscle, Nox1 is thought to be involved in blood pressure regulation (10-12), but it is expressed at much higher levels in the colon, where its function remains unresolved. Nox 3 is crucial for the genesis of otoconia (also known as otoliths) (13), which are tiny calcium carbonate crystals in the inner ear that are required for sensing gravity. The biological roles of Nox 4 and Nox 5 have not yet been established.

The cytosolic Phox subunits each have one homolog: Nox organizer 1 (Noxo1) and Nox activator 1 (Noxa1) are the respective paralogs of $\mathrm{p} 47^{\text {phox }}$ and p67phox (14-16). In transfected cell lines, Noxo1 and Noxa1 are required for the enzymatic activities of Nox1 and Nox3 (14-18). Moreover, Noxo1 has been shown to be essential for Nox3 function in vivo (19). Interestingly, $\mathrm{p} 22^{\text {phox }}$ is the only key component of Phox that is unique - it has no paralogs, in either humans or rodents. In transfected cells, p2 $2^{\text {phox }}$ expression is a prerequisite for the enzymatic activities of 3 gp $91^{\text {phox }}$ homologs: Nox1, Nox3, and Nox4 (20-24). Whether p22 $2^{\text {phox }}$ serves as a subunit of any of the novel, nonphagocytic Nox complexes in vivo and whether it functions outside the antibacterial host defense system is unknown.

Here we describe the molecular and phenotypic characterization of what we believe to be a previously unrecognized p22 phox-deficient mouse strain, nmf333, which was generated in the course of an ethylnitrosourea-induced mutagenesis project at The Jackson Laboratory. Our analysis of the nmf333 phenotype indicates that the $\mathrm{p} 22^{\text {phox }}$ deficiency causes a syndrome characterized not only by CGD, but also by a severe balance disorder. In addition, the localization of p22phox in the embryonic inner ear epithelium sug- 

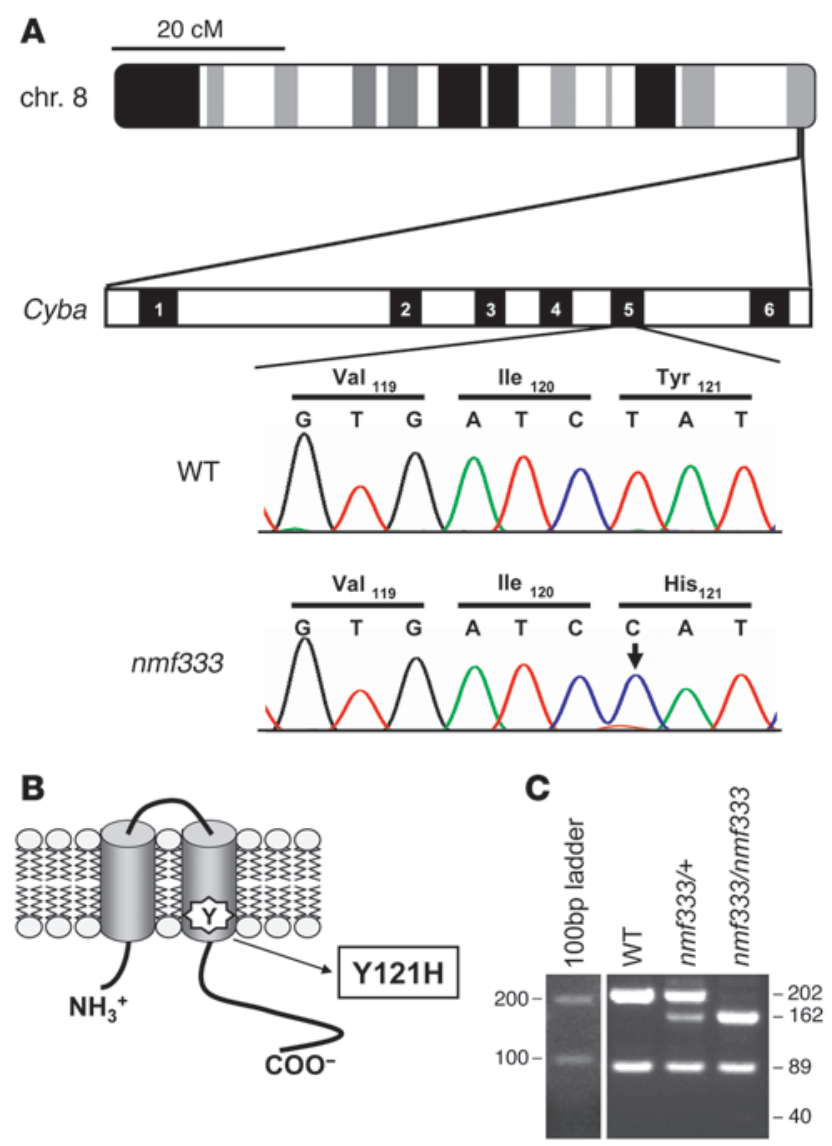

Figure 1

Missense mutation in the Cyba gene of the nmf333 mouse strain. (A) The p22 $2^{\text {phox }}$-encoding Cyba gene is located near the distal telomere of mouse chromosome 8 (top ideogram). Cyba contains 6 exons (numbered black boxes). A deoxythymidine nucleotide (T) in exon 5 of WT Cyba (upper chromatogram) is replaced by a deoxycytosine (C) in the nmf333 mutant strain, as indicated by an arrow in the lower chromatogram. The point mutation changed the 121st amino acid of $\mathrm{p} 22^{\text {phox }}$ from tyrosine (Tyr) to histidine (His), as shown in the translation lines. (B) The tyrosine to histidine amino acid substitution $(\mathrm{Y} 121 \mathrm{H})$ is localized to the second predicted transmembrane helix of p22 ${ }^{\text {phox }}$. (C) Genotyping for the nmf333 mutation with PCR amplification and subsequent $B s / l$ digestion of a fragment of the Cyba gene. Lanes show a 100-bp ladder and the genotyping results using DNA samples from WT, heterozygous nmf333 (nmf333/+), and homozygous nmf333 (nmf333/nmf333) mice. Fragment sizes are given in bp.

gests a mechanism whereby a nonphagocytic Nox complex might control organ development.

\section{Results}

The $n m f 333$ mouse strain carries missense mutation in the gene encoding $p 22^{\text {phox }}$. The 3 closest structural homologs of gp91 phox (i.e., Nox1, Nox3, and Nox4) have been reported to produce superoxide in transfected cell lines only when $2^{2} 2^{\text {phox }}$ is coexpressed. Thus, we speculated that, in vivo, $\mathrm{p}^{2} 2^{\text {phox }}$ deficiency would lead to a phenotype that combines defects of gp91 phox, Nox1, Nox3, and Nox4. Of the 4 enzymes, only Nox3 is associated with a readily visible phenotype under specific pathogen-free conditions - a balance disorder (13). Therefore, we searched mutant mouse databases for signs of a balance-deficient phenotype. The nmf333 strain was selected for further analysis because (a) it was reported to exhibit a recessively inherited head and body tilt (25), and (b) the disease-causing mutation had been mapped to a position $67 \mathrm{cM}$ distal to the centromere of mouse chromosome 8 (Figure $1 \mathrm{~A})$, which corresponds to the region where the p22phox-encoding cytochrome $\mathrm{b} \alpha$ subunit (Cyba) gene is located. Sequence analysis of the Cyba gene of nmf333 mice revealed a $T$ to $C$ point mutation in exon 5 , resulting in a tyrosine to histidine substitution at amino acid position 121 of p22phox (Figure 1A). The mutated tyrosine is located within a predicted transmembrane domain of the protein (Figure 1B); thus, it is likely to have profound structural consequences. The identified $\mathrm{T}$ to $\mathrm{C}$ point mutation also altered the restriction digestion pattern of $C y b a$, thereby facilitating genotype determination (Figure 1C).

The Tyr121His substitution eliminates $p 22^{\text {phox }}$ protein expression and superoxide production in phagocytes. Given that $\mathrm{p} 22^{\text {phox }}$ is a critical subunit of Phox, we studied the effect of the Tyr121His $(\mathrm{Y} 121 \mathrm{H})$ substitution in the most common phagocytic cell type - neutrophil granulocytes. The identified point mutation did not diminish p22 phox mRNA expression; RT-PCR analysis revealed that the mutant transcript was present at normal levels in the spleens of nmf333 mice (data not shown). However, Western blot experiments demonstrated that $\mathrm{p} 22^{\text {phox }}$ protein was absent from the neutrophil granulocytes of homozygous nmf333 mice (Figure $2 \mathrm{~A})$. In contrast, $\mathrm{p} 22^{\text {phox }}$ expression was readily detected in the neutrophils of WT littermates (Figure 2A). Therefore, the Y121H amino acid substitution interferes with either the synthesis or stability of the $\mathrm{p}^{22^{\text {phox }}}$ protein.

Because of the absence of $\mathrm{p} 22^{\text {phox }}$ expression, the $n m f 333$ mutation of Cyba was expected to obliterate superoxide production in phagocytes. We used the ferricytochrome c assay to quantify the rates of superoxide generation in WT and $n m f 333 / n m f 333$ neutrophils in the presence and absence of PMA, which activates superoxide generation through the PKC signaling pathway (26). Neutrophils from homozygous $n m f 333$ mutant mice did not produce detectable levels of superoxide, either in the presence or absence of the stimulus (Figure 2B), whereas PMA-activated WT cells generated superoxide at previously described levels (27). Although the ferricytochrome $\mathrm{c}$ assay provides quantitative data, it measures only extracellular superoxide. Therefore, we further examined Nox activity in $n m f 333 / n m f 333$ neutrophils using the luminol-enhanced HRP-dependent chemiluminescence technique, which detects both intra- and extracellular ROS with great sensitivity. The luminol assay indicated the complete absence of Nox activity in $n m f 333 / n m f 333$ neutrophils, in stark contrast with the apparent signal detected in the neutrophils of WT littermates (Figure 2C). Thus, the identified $n m f 333$ mutation produces a p22phox knockout at the level of protein expression and eliminates the enzymatic activity of Phox.

The p22phox-deficient nmf333 strain is bighly susceptible to necrotizing pneumonia. Burkholderia cepacia is an emerging opportunistic pathogen that causes fatal pneumonia in patients with CGD (28). Despite its clinical importance, the course of $B$. cepacia lung infection has not yet been studied in the existing gp91phox - and $\mathrm{p} 47$ phox deficient mouse models of CGD. Nonetheless, we chose a clinical isolate of B. cepacia (genomovar I) and inoculated the tracheas of homozygous nmf333 mice and WT littermates with $10^{6} \mathrm{CFU}$ of this infectious agent. Anesthetized mice inhaled the drop of inoculum from the tracheal lumen, and the airflow disseminated the liq- 
A

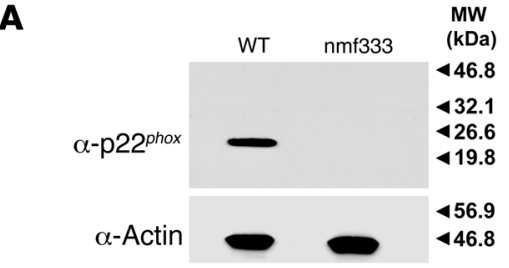

в
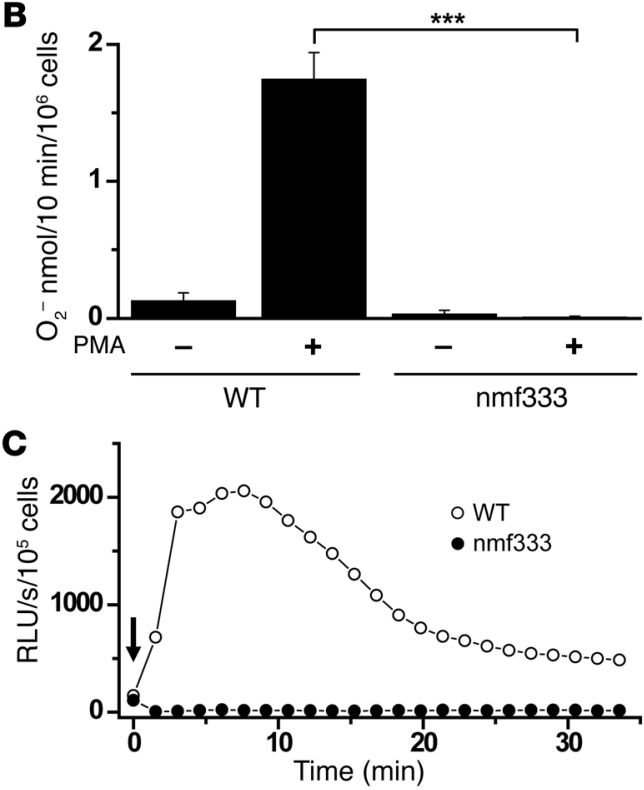

uid to both halves of the lung, as determined in a pilot experiment using bromophenol blue solution (data not shown). WT mice infected with $B$. cepacia $\left(10^{6} \mathrm{CFU}\right.$ in $\left.25 \mu \mathrm{l} \mathrm{HBSS}\right)$ recovered swiftly from the infection, and none of these animals died during the entire span of the experiment (Figure 3A). In contrast, all $n m f 333$ / $n m f 333$ mice inoculated with $10^{6} \mathrm{CFU}$ B. cepacia succumbed to the infection within 3 days. In fact, the pneumonia was so fulminant in the mutant mice that the first signs of lung disease (e.g., grunting and wheezing breathing sounds) were followed by death in fewer than 24 hours. Disease progression was only slightly slower when the inoculum was decreased to either $10^{5}$ or $10^{4} \mathrm{CFU}$ (Figure $3 \mathrm{~A})$. Control $n m f 333 / n m f 333$ animals that were inoculated with only sterile HBSS showed no signs of illness. These experiments demonstrate that $\mathrm{p} 22^{\text {phox }}$-deficient $\mathrm{nmf} 333$ mice have a severely increased susceptibility to B. cepacia lung infection.

To evaluate bacterial clearance in the respiratory tracts of $\mathrm{p} 22^{\text {phox }}$ deficient mice and their WT littermates, we determined the number of surviving bacteria in the lungs 3.5 days after intratracheal inoculation with $10^{4} \mathrm{CFU}$ B. cepacia. The lung homogenates of WT mice did not contain bacteria, whereas the lungs of $\mathrm{p}^{22} 2^{\text {phox }}$-deficient littermates contained more than $10^{8} \mathrm{CFU}$ B. cepacia (Figure $3 \mathrm{~B}$ ). Moreover, the severe immunodeficiency of the nmf333 strain allowed the infection to become systemic, as evidenced by large numbers of B. cepacia recovered from the spleens of $n m f 333 / n m f 333$ mice (Figure $3 \mathrm{~B}$ ). In contrast, the spleens of WT littermates were devoid of bacteria (Figure 3B).

To assess the histological changes in response to $B$. cepacia infection, we investigated lung and spleen tissue sections obtained 3.5 days after the intratracheal inoculation with bacteria $\left(10^{4} \mathrm{CFU}\right)$. In WT mice, lungs appeared almost normal, with minimal granulocytic

\section{Figure 2}

Lack of $22^{\text {phox }}$ expression and superoxide production in the neutrophil granulocytes of homozygous nmf333 mice. (A) Immunoblot detection of p22phox in the SDS-PAGE-separated protein lysate of WT neutrophils. The $\mathrm{p}_{22^{\text {phox }}}$ band is absent from the lysate of $\mathrm{nmf333}$ neutrophils (top). Comparable protein loading is demonstrated by the actin signal present in both samples (bottom). Arrowheads and numbers indicate the positions of MW standards. (B) Rate of superoxide production by nonstimulated (-) and PMA-activated (+) neutrophil granulocytes isolated from the bone marrow of WT and homozygous nmf333 mice, as measured using the superoxide dismutase-sensitive cytochrome $c$ reduction assay. Bars represent mean $\pm \operatorname{SEM}(n=3-5)$. ${ }^{* \star} P=0.0005$; unpaired 2-tailed $t$ test. (C) Superoxide production of neutrophil granulocytes isolated from the bone marrow of WT (open circles) and homozygous nmf333 (filled circles) mice and stimulated with PMA (arrow), as detected by luminol-amplified chemiluminescence. Traces are representative of $n=3$. RLU, relative light units.

infiltration into the peribronchial and perivascular areas (Figure $3 C)$. In $n m f 333 / n m f 333$ mice, however, the lung tissue was greatly damaged by necrotizing pneumonia, and the alveolar spaces were filled with neutrophil granulocytes, macrophages, and cell debris. Similar differences were observed in spleen sections from these animals: no histological changes were found in WT mice, whereas the spleens of infected $n m f 333 / n m f 333$ animals contained necrotic areas and increased numbers of polymorphonuclear cells within the marginal zone and the red pulp (Figure 3C). These experiments demonstrate that, despite the massive inflammatory response, B. cepacia is not eliminated from the respiratory tract in the nmf333 strain, which allows the infection to become systemic.

p22 phox-deficient mice exhibit a second phenotype - a balance disorder. In the ethylnitrosourea mutagenesis project that produced the nmf333 strain, the founder mutant mice were identified on the basis of their head and body tilt. We characterized further the indicated balance disorder using classic swimming tests and measurements of vestibular-evoked potentials (VsEPs). In the swimming tests, the severe vestibular defect of $n m f 333 / n m f 333$ mice was demonstrated by their inability to remain at the surface of the water, whereas heterozygous and WT littermates were good swimmers (Figure 4A). For the VsEP measurements, we recorded the electroencephalographic responses to short linear accelerations applied to the heads of anesthetized mice. The encephalograph of $n m f 333$ / $n m f 333$ animals indicated nonresponsiveness, even at maximal linear accelerations. In contrast, when age- and strain-matched WT and heterozygous mice were tested, the thresholds of VsEPs were in the normal range (Figure 4, B and C).

Together, the findings of the swimming and electrophysiological tests indicate that the balance defect in the nmf333 strain is severe and similar to that of otoconia-deficient Nox3, Noxo1, and otopetrin 1 mutant mice $(13,19,29)$. We therefore studied the inner ear histology of $n m f 333 / n m f 333$ mice. Although tissue staining with hematoxylin and eosin showed a normal overall inner ear structure in the mutants (data not shown), the von Kossa method - which reveals calcium salts in tissue sections - demonstrated a lack of otoconia in the utricles and saccules of newborn $n m f 333 / n m f 333$ mice. In contrast, heterozygous and WT animals at the same developmental stage had numerous otoconia in both structures (Figure 4D). Higher-resolution images generated by scanning electron microscopy confirmed the total absence of otoconia in developing $n m f 333 / n m f 333$ mice (Figure 4E), which suggested that p22 phox is required for the initial steps of otoconial crystal formation. 
A

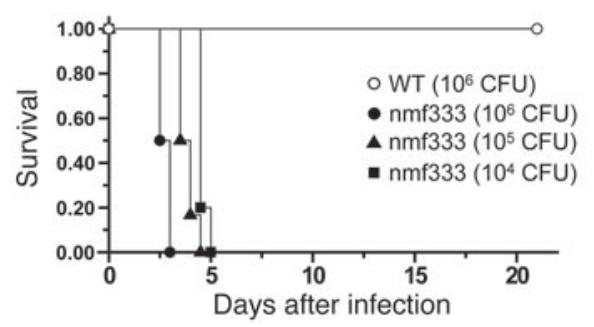

B

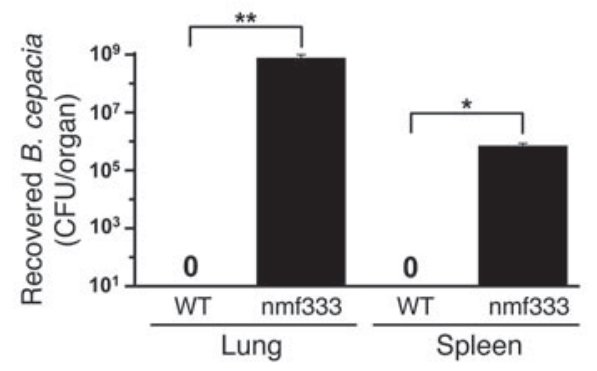

C

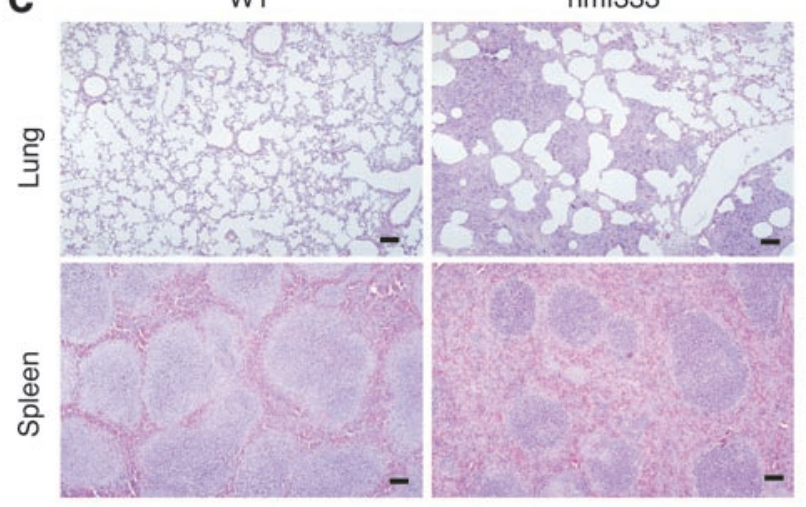

Because otoconia are indispensable for sensing gravity and other linear accelerations, the vestibular and motor coordination deficits of the nmf333 line can be explained by the lack of otoconia. Hearing was unaffected by the $n m f 333$ mutation (Supplemental Figure 1; supplemental material available online with this article; doi:10.1172/JCI33835DS1).

p22 phox protein is expressed in the endolymphatic sac and duct. The genesis of otoconia begins in the developing utricle and saccule on E14 (30). Therefore, we expected p22phox to be localized to the embryonic utricle and saccule of WT mice. However, both of these organs were completely devoid of p22phox immunostaining at E14 (data not shown). Thus, we expanded the search for $\mathrm{p} 22^{\text {phox }}$ expression to the entire inner ear. Surprisingly, strong immunofluorescence was detected in the upper part of the endolymphatic duct (Figure $5 \mathrm{~A}$, left) and in the lower area of the endolymphatic sac (data not shown). The same structures in the inner ears of the $n m f 333$ / nmf333 mice did not exhibit p22 phox staining (Figure 5A, right), thereby confirming that homozygous nmf333 mice lack p22phox protein. By E17, p22 phox expression was extended to a large portion of the endolymphatic duct in WT embryos. By birth, the p22phox signal was restricted to a lower section of the endolymphatic duct that channels into the saccule and utricle (Figure 5C). By P12, p22 phox became undetectable in the endolymphatic duct (data not shown). Throughout inner ear development, p22 phox was consistently localized to the apical regions of a subset of epithelial cells.

\section{Figure 3}

Necrotizing pneumonia in homozygous nmf333 mice following B. cepacia lung infection. (A) Probability of survival after inoculation with various $\mathrm{CFU}$ of $B$. cepacia $\left(10^{4} \mathrm{CFU}\right.$, filled squares; $10^{5} \mathrm{CFU}$, filled triangles; $10^{6} \mathrm{CFU}$, open circles and filled circles) into the tracheas of WT (open circles; $n=8$ ) and nmf333 (filled circles, filled triangles, filled squares; $n=5$ or 6 ) mice. $P=0.0009$ between the $10^{6}$ CFU infected WT and nmf333 groups; log-rank test. (B) Number of B. cepacia recovered from the lung and spleen homogenates of WT and homozygous nmf333 mice 3.5 days after intratracheal inoculation with $10^{4} \mathrm{~B}$. cepacia, as evaluated by quantitative culture; bacteria were not detected in lung and spleen homogenates from WT mice. Bars represent mean $\pm \operatorname{SEM}(n=3) .{ }^{* *} P=0.029,{ }^{*} P=0.043 ; t$ tests with 2 degrees of freedom. (C) Histopathological appearance of lung and spleen sections obtained from WT and homozygous nmf333 mice 3.5 days after intratracheal inoculation with $10^{4}$ CFU B. cepacia. Whereas WT tissue samples had minimal or no inflammation, necrotizing pneumonia and splenitis were apparent in the nmf333 strain. Hematoxylin and eosin staining were used. Scale bars: $100 \mu \mathrm{m}$.

These results indicate that the inner ear Nox is not expressed at the site of otoconial genesis, but rather at a distance - in the apical membrane of the endolymphatic duct and sac epithelia.

Transgenic expression of $2_{22^{p h o x}}$ rescues the host defense defect of $n m f 333$ mice. We used transgenic rescue to definitively prove that the identified mutation in Cyba is responsible for the immunodeficiency and balance disorder exhibited by mice of the nmf333 strain. Previous studies suggested that the Cyba gene product, $\mathrm{p} 22^{\text {phox }}$, is unstable unless dimerized with a Nox protein (31). Therefore, we reasoned that ubiquitous $\mathrm{p} 22^{\text {phox }}$ mRNA expression would lead to $\mathrm{p} 22^{\text {phox }}$ protein expression in the endolymphatic duct and sac as well as in phagocytes, without adverse side effects. Thus, we constructed a Cyba transgene that was controlled by the ubiquitously active $\beta$-actin promoter. The transgene construct also contained a CMV immediate-early enhancer, an artificial intron, and an SV40 polyadenylation site for high-level synthesis of stable mRNA (Figure 6A). Pronuclear injection of the p22 $2^{\text {phox }}$-expression cassette led to the generation of 8 transgenic founder mice in a WT genetic background. The transgenic founders were bred with the nmf333 strain for 2 to 4 consecutive backcross generations to generate Cyba-transgenic nmf333/nmf333 animals.

Cyba transgene-positive $n m f 333 / n m f 333$ mice were first screened for Phox activity. Peripheral blood neutrophils were obtained from the tail vein, and superoxide production was assessed using nitroblue tetrazolium (NBT), which forms blue precipitate upon reacting with superoxide. PMA-stimulated neutrophils from 6 of the 8 transgenic lineages (in the $n m f 333 / n m f 333$ genetic background) produced positive NBT tests (Figure 6B), whereas PMA-stimulated neutrophils of nontransgenic $n m f 333 / n m f 333$ mice were consistently NBT negative. To evaluate the extent of the functional rescue, we applied the quantitative ferricytochrome $\mathrm{c}$ assay and observed a wide range of superoxide-generating capacity in neutrophils from individual Cyba-transgenic nmf333/nmf333 mice (Figure $6 \mathrm{C}$ ). These findings indicate that the Cyba transgene restores Phox activity to various levels, which probably reflects differences in transgene copy number and insertion sites.

The consequences of transgenic rescue for the host defense system were examined using the B. cepacia infection model. We found that most of the Cyba transgene-positive $n m f 333 / n m f 333$ mice recovered from $B$. cepacia $\left(10^{4} \mathrm{CFU}\right)$ lung infection (Figure $\left.6 \mathrm{D}\right)$. Although some of the transgenic animals did succumb to pneumo- 
A
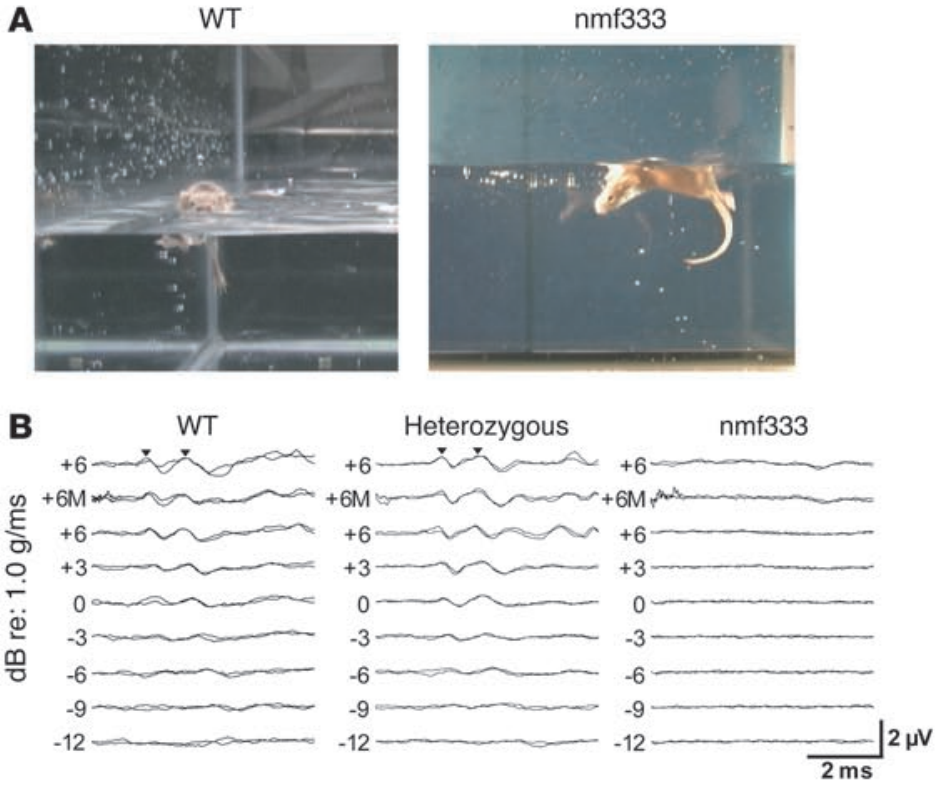

C

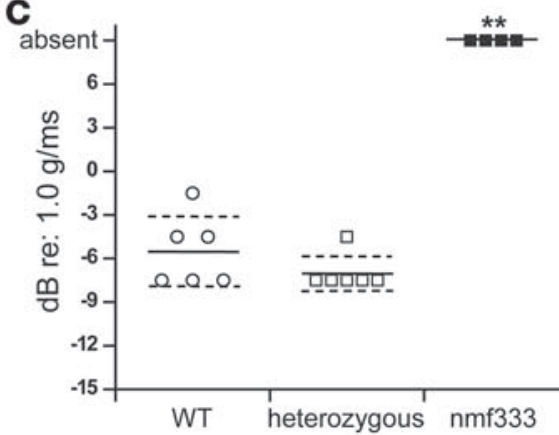

D

WT
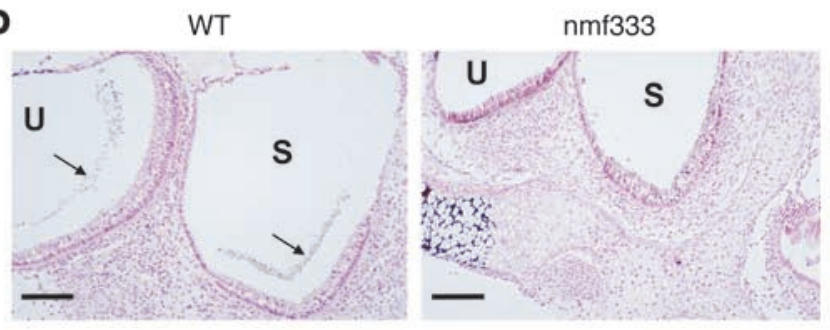

$\mathbf{E}$
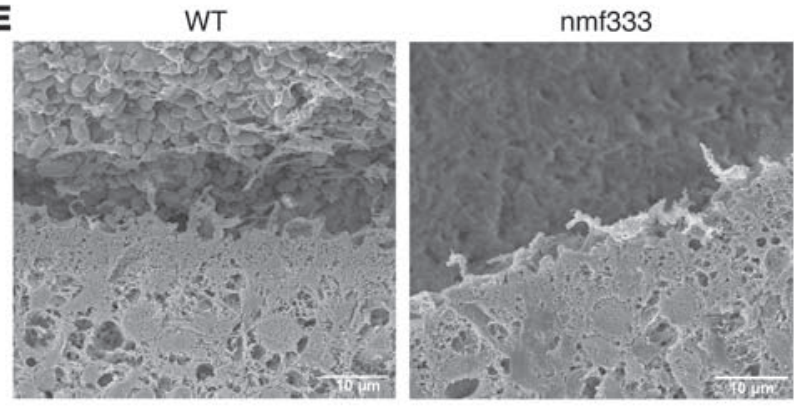

nia, this occurred at later time points than in their transgene-negative $n m f 333 / n m f 333$ counterparts. This finding is in good agreement with the quantitative superoxide production data, which indicated a broad range of rescue efficiency by the transgene. Our results also suggest that the reconstitution of superoxide genera-

\section{Figure 4}

Balance organ dysfunction and a lack of otoconia in nmf333 mice. (A) Balance in WT and homozygous nmf333 mice was examined using swimming tests. Homozygous mutants were unable to orient themselves in water and swirled under the surface. (B) Balance function based on VsEP waveforms; 2 representative replicates of VsEP waveforms are shown for WT, heterozygous, and homozygous mutant nmf333 mice exposed to linear acceleration stimuli from +6 to $-12 \mathrm{~dB}$ relative to reference intensity (re) $1.0 \mathrm{~g} / \mathrm{ms}$ in 3-dB increments, with auditory masking $(\mathrm{M})$ and without auditory masking. Positive-response peaks are labeled with arrowheads. VsEP responses were absent in $n m f 333 / n m f 333$ mice. (C) Summarized VsEP data. Individual VsEP thresholds are shown for WT (open circles; $n=6$ ), heterozygous (open squares; $n=6$ ), and $n m f 333 / 333$ (filled squares; $n=4$ ) mice. Mean thresholds are indicated by solid horizontal lines \pm 1 SD (dashed lines). $P<0.0001$, 1-way ANOVA; post-hoc Dunnett's test between WT and heterozygous $(P>0.05)$ and between WT and nmf333 groups $\left({ }^{* *} P<0.01\right)$. (D) Otoconial presence determined by von Kossa staining. The von Kossa method revealed the calcium salt content characteristic of otoconia (arrows) in the saccule $(\mathrm{S})$ and utricle $(\mathrm{U})$ of a WT mouse. No calcium salts are present in the utricle and saccule of nmf333 mice. $n=3$ per group. Scale bars: $100 \mu \mathrm{m}$. (E) Otoconial presence was investigated by scanning electron microscopy in the saccules of WT and homozygous nmf333 mice. The otoconial crystal layer is completely absent from the nmf333 saccule.

tion to only low levels is not sufficient to prevent CGD. The greatly improved host defense capacity of most Cyba transgene-rescued mutants was confirmed by the substantially reduced tissue damage and inflammatory responses evoked by B. cepacia lung infection (compare Figure 6E with Figure $3 C$ ). These results prove that the Cyba gene defect is responsible for the immune deficiency that leads to lethal pneumonia in nmf333 mice upon B. cepacia infection.

The Cyba transgene rescues the balance defect in the nmf 333 strain. To test whether the balance disorder in the nmf333 strain is also caused by the identified mutation in Cyba, we assessed inner ear histology and balance phenotype in Cyba-transgenic nmf333 mice. The Cyba transgene was active in the inner ear, as $\mathrm{p} 22^{\text {phox }}$ expression was restored in the endolymphatic duct of Cyba-transgenic nmf333/nmf333 animals (Figure 7A). Moreover, otoconia of apparently normal shape and number were present in the utricles and saccules of transgene-positive homozygous mutants (Figure $7 \mathrm{~B})$, which is in contrast with the findings for the parental nmf333 strain (Figure 4D). The restoration of otoconial crystals and vestibular function in the transgene-rescued nmf333 mice was indicated by swimming tests: Cyba-transgenic $n m f 333 / n m f 333$ mice remained afloat, whereas the nontransgenic homozygous mutants could not orient themselves in water and dived (compare Figure 7C with Figure 4A). Next, we used fixed-speed rotarod treadmill tests to quantify the balancing ability and motor coordination of $n m f 333 / n m f 333$ mice, littermate WT animals, and Cybatransgenic $n m f 333 / n m f 333$ mice. Following 2 rotarod training sessions, we measured the time in which each mouse could remain on the rotating cylinder (day 1 [d1], Figure 7D). Without additional training, measurements were repeated on 2 consecutive days $(\mathrm{d} 2$ and d3, Figure 7D). On day 3, each tested WT mouse was able to 
A

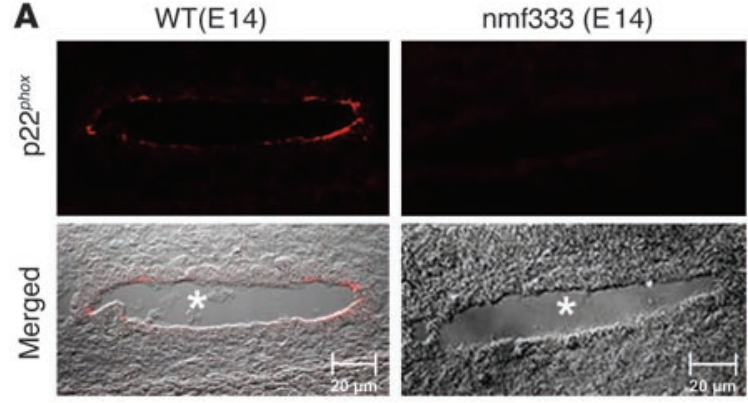

B
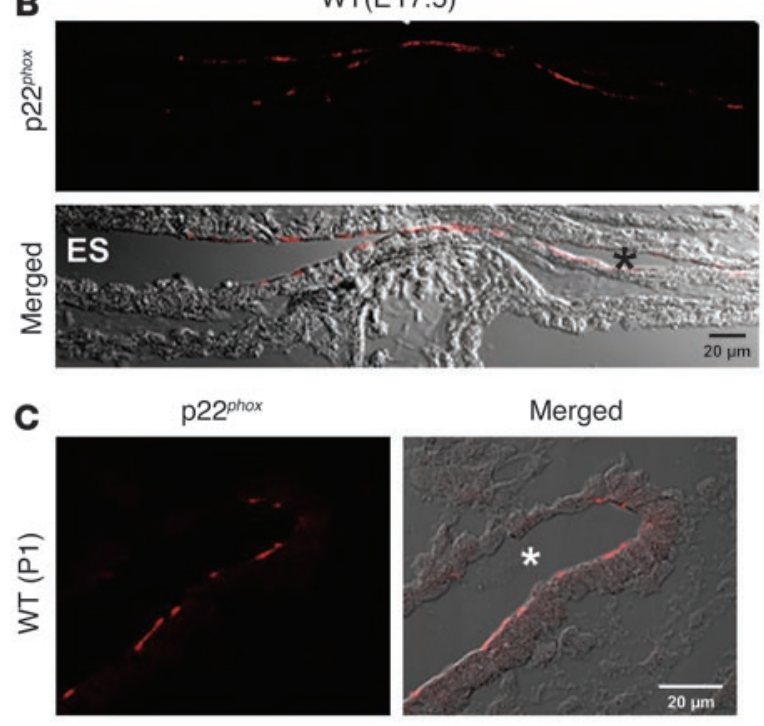

remain on the rotarod for the entire duration of the assay (180 s), whereas $n m f 333 / n m f 333$ mice fell within seconds. Most homozygous mutants overran the speed of the rotarod, leading to the extremely short latency to fall. The rotarod test performance of Cyba-transgenic nmf $333 / \mathrm{nmf} 333$ mice was indistinguishable from that of WT animals, demonstrating the rescue effect of the Cyba transgene on the balancing ability of nmf333 mice (Figure 7D). To further quantify balance organ function in the transgenic mice, we used VsEP assays. Cyba-transgenic nmf333/nmf333 mice exhibited VsEP thresholds similar to those of WT animals (compare Figure 7E with Figure 4C) and significantly lower than those of homozygous nmf333 mice (Figure 7E). These transgenic rescue experiments demonstrate that the lack of $\mathrm{p} 22^{\text {phox }}$ expression is responsible for the vestibular disorder in the nmf333 strain.

\section{Discussion}

The results described in this study show that a lack of p22phox expression leads to severe balance and immune disorders. These 2 phenotypes in the p $22^{\text {phox }}$-deficient mice reflect the functional importance of p2 $22^{p h o x}$ to the Noxes of both the inner ear and phagocytes. Our results do not rule out that $\mathrm{p} 22^{\text {phox }}$ is also required for the function of Nox proteins other than gp91phox and Nox3. Indeed, previous studies in transfected cell lines have indicated that $\mathrm{p} 22^{\text {phox }}$ is essential to the enzymatic activities of Nox 1 and Nox4 (22-24). However, our experiments provided no in vivo evidence for such a role because we found no histological abnormalities in the main Nox1- and Nox4-expressing tissues - the colon

\section{Figure 5}

Expression of p22 phox in the apical membrane of endolymphatic duct and sac. (A) Endolymphatic duct sections of a WT and a homozygous nmf333 mouse at E14 were immunostained with an anti-p22phox antibody and visualized by confocal microscopy. Top: localization of the immunofluorescence signal (p22 phox). Bottom: superimposition of the fluorescence signal and the differential interference contrast image (merged). Asterisks indicate endolymphatic duct lumens. (B) Immunostaining of WT endolymphatic sac (ES) and duct (asterisk) with the anti-p22phox antibody at E17.5. Top: red fluorescence signal of p22 phox immunolocalization. Bottom: superimposition of the fluorescence signal and the differential interference contrast image (merged). (C) In P1 WT mice, the lower region of the endolymphatic duct exhibits p22 $2^{\text {phox }}$ immunofluorescence (left). Right: both the red fluorescence signal and the differential interference contrast image. The asterisk indicates the lumen of the endolymphatic duct. Scale bars: $20 \mu \mathrm{m}$.

and kidney - of p22 phox-deficient mice (data not shown). Clearly, further studies are required to assess the importance of $\mathrm{p} 22^{\text {phox }}$ to the biological functions of Nox1 and Nox4.

To our knowledge, the Cyba mutant nmf333 strain is the first animal model for p22 phox-deficient CGD. The immune defects of CGD patients and of nmf333 mice have certain fundamental similarities: the lack of superoxide generation by neutrophil granulocytes and the extraordinary susceptibility to B. cepacia pneumonia. Therefore, the nmf333 strain will be a valuable model for investigating the pathogenesis of CGD and for developing gene therapy approaches for ameliorating the effects of $\mathrm{p} 22^{\text {phox }}$ deficiency. Although balance deficits have not been reported in p22phoxnegative CGD patients, such deficits could be underappreciated because of the rarity of the disease or rendered cryptic by compensatory activity of the central nervous system. Indeed, the balance defect of the nmf333 strain is most severe in young animals. Although aging nmf333 mice never pass the swimming test, their head and body tilt often becomes less evident; this could reflect a learned ability to compensate for the lack of gravity organ function using information from the semicircular canals as well as visual and tactile cues (32). Therefore, we suggest that a balance disorder in p22phox-deficient CGD patients may become apparent only when the function of their otolith organs is specifically tested.

On the basis of the expression pattern of the $\mathrm{p} 22^{\text {phox }}$ subunit, the entire inner ear oxidase complex is likely to be located in the endolymphatic sac and duct. These data also indicate that the endolymphatic sac and duct play a special role in the formation of otoconia in addition to their previously known functions in the regulation of endolymph volume. Localization of other inner ear Nox subunits (i.e., Nox3 and Noxo1) had been previously investigated only at the mRNA level $(18,19)$. These studies found Nox3 and Noxo 1 mRNA in the cochlea and vestibular system; the endolymphatic duct and sac were not examined. The broader distribution of Noxo 1 and Nox 3 mRNA than of the $\mathrm{p}^{22^{\text {phox }}}$ protein may be explained by an incomplete coordination of the expression of inner ear Nox subunits, by the high sensitivity of the mRNA-detection methods used, and/or by the fact that the low abundance of mRNA molecules may not accurately reflect the expression of corresponding protein products (33).

How is a Nox able to control otoconial formation? The p22phox expressing epithelium is not directly adjacent to the sites of otoconial genesis. Because ROS are unstable and some of them (e.g., hydrogen peroxide) readily diffuse across biological membranes, it 


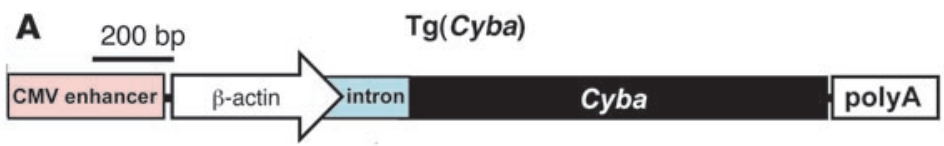

B
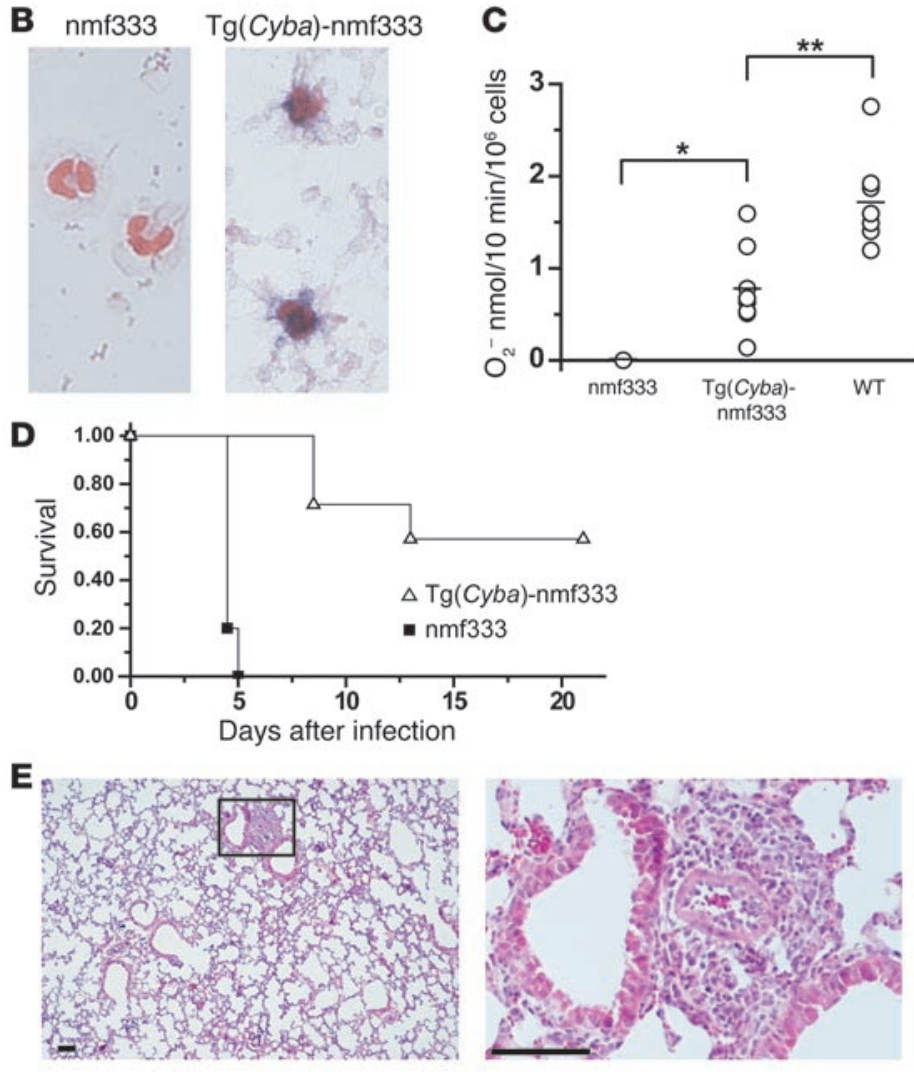

\section{Figure 6}

The Cyba transgene reduces the $B$. cepacia susceptibility of the nmf333 strain. (A) The Cyba transgene consists of a CMV immediate-early enhancer, a chicken $\beta$-actin promoter, a chimeric intron, the p22 ${ }^{\text {phox }}$-encoding $C y b a$ sequence, and an SV40 polyadenylation (polyA) site. (B) Blue colorimetric test for superoxide production in PMA-stimulated neutrophil granulocytes isolated from homozygous nmf333 mice and from Cybatransgenic homozygous nmf333 [ $\mathrm{Tg}(C y b a)-n m f 333]$ mice. Two neutrophils are visible in each. Nuclei were stained with Safranin 0 . Original magnification, $\times 63$. Images are representative of $n=38$. (C) Quantitative analysis of superoxide production by PMA-activated neutrophil granulocytes isolated from homozygous nmf333 mice, Cyba-transgenic homozygous nmf333, and WT mice. Superoxide production was assessed using the superoxide dismutase-sensitive ferricytochrome $\mathrm{c}$ reduction assay. Horizontal lines indicate the mean rate of superoxide production; each circle represents a single mouse $(n=5$ to 8 mice). One-way ANOVA, $P<0.0001$. post hoc Tukey's test: ${ }^{\star} P<0.05,{ }^{* *} P<0.01$. (D) Probability of survival of homozygous nmf333 mice (filled squares; $n=5$ ) and of Cyba-transgenic homozygous nmf333 mice (open triangles; $n=7$ ) after intratracheal inoculation with $10^{4} \mathrm{CFU} B$. cepacia (log-rank test, $P=0.0004)$. (E) Typical histological appearance of lung sections prepared from Cyba-transgenic homozygous nmf333 mice 3.5 days after intratracheal inoculation with $10^{4} \mathrm{CFU}$ B. cepacia $(n=3)$. Left: low-magnification overview. Right: higher-magnification view of peribronchial inflammation in the boxed region. Scale bars: $100 \mu \mathrm{m}$. is unlikely that they travel from the endolymphatic sac and duct to the utricle and saccule, despite the fact that these organs are connected. Previous hypotheses have suggested that the role of the inner ear Nox is to trigger crystal nucleation by oxidizing the organic components of otoconia, including the main matrix protein otoconin-90 $(13,19)$. In light of new data, however, such hypotheses are less compelling. Not only has a recent study shown that otoconin-90 is dispensable for calcium carbonate crystal nucleation (34), but the distance between the oxidase-expressing cells and the site of otoconia formation appears to be prohibitive. These findings, together with the electrical properties of plasma membrane Nox cytochromes, led us to propose a previously unexpected mechanism for the Nox-mediated control of otoconial genesis.

The crystallization of calcium carbonate occurs by an acid-base reaction that requires high calcium and bicarbonate concentrations as well as an alkaline $\mathrm{pH}(35)$. However, the calcium concentration $(0.2 \mathrm{mM})$ and $\mathrm{pH}(7.4)$ of the adult vestibular endolymph are both too low to support calcium carbonate precipitation $(36,37)$. We suggest that these ionic conditions are altered in the embryonic inner ear by a plasma membrane oxidase. Noxes produce superoxide by transporting electrons from intracellular NADPH to extracellular oxygen, and, as electrons are exported from the cell, the plasma membrane becomes depolarized $(38,39)$. Depolarization of the apical membrane would not only prevent cellular $\mathrm{Ca}^{2+}$ uptake (40) from the endolymph, but could also increase paracellular ion permeability (41), which would then lead to $\mathrm{Ca}^{2+}$ influx from the perilymph to the endolymph because of a 6-fold $\mathrm{Ca}^{2+}$ concentration gradient. In addition, the oxidase-generated superoxide would likely react with protons in the endolymph and thereby elevate the $\mathrm{pH}$, as has been described in the phagosome of neutrophil granulocytes (42). Because the mobility of $\mathrm{H}^{+}$in aqueous solution is outstandingly high compared with that of other ions (43), the $\mathrm{pH}$ changes in the endolymphatic duct are likely to affect the proton concentration in the utricle and saccule where otoconia are formed. Although the mechanism of $\mathrm{pH}$ regulation in the inner ear is not completely understood (44), the importance of alkaline $\mathrm{pH}$ in otoconial genesis has been indicated by the phenotype of mice defective for pendrin, a $\mathrm{HCO}_{3}{ }^{-} / \mathrm{Cl}^{-}$exchanger expressed in the endolymphatic duct and sac as well as in the cochlea $(45,46)$. In pendrin-deficient animals, the endolymphatic $\mathrm{pH}$ is abnormally low, and otoconia are either absent altogether or replaced by giant crystals (36). In summary, we propose that the inner ear Nox has the capacity to generate ionic conditions favoring the crystallization of calcium carbonate and thereby to promote the formation of otoconia.

\section{Methods}

Mutant and transgenic mouse strains. Heterozygous nmf333 mice (A.B6-Tyr ${ }^{+} / \mathrm{J}$ genetic background) were obtained from The Jackson Laboratory. Cybatransgenic mice (C57BL/6 $\times$ SJL.F2 genetic background) were produced at the Xenogen Corp. by microinjecting a p2 $2^{\text {phox }}$-expression cassette (i.e., Cyba transgene) into pronuclei of fertilized oocytes that were transferred 
A
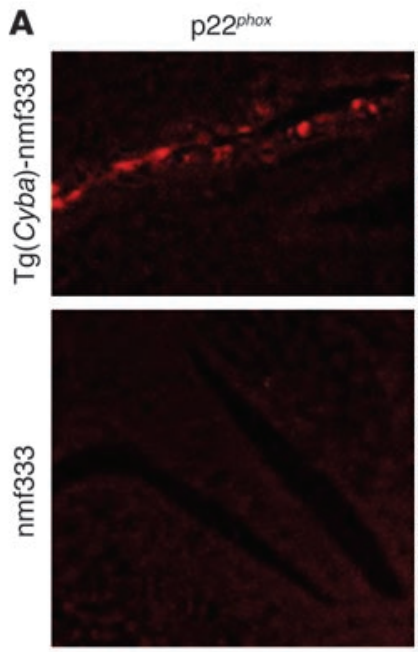

B

B $\quad \operatorname{Tg}($ Cyba) $-\mathrm{nmf333}$
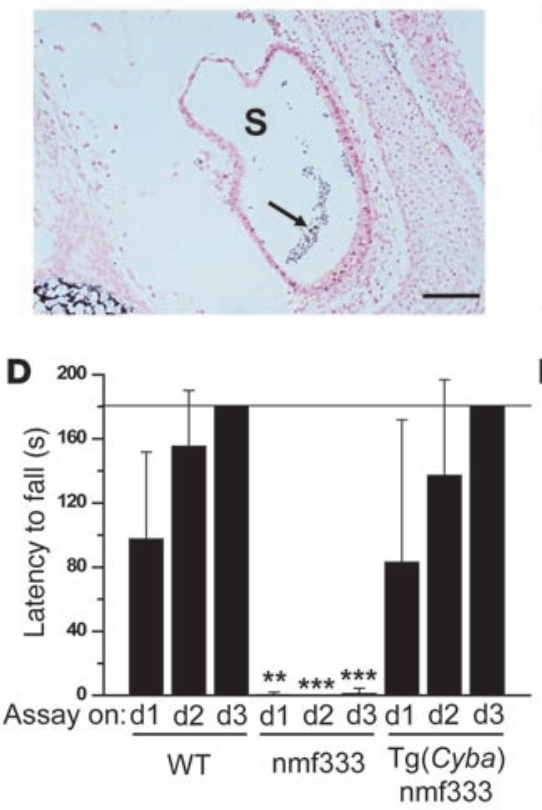

Merged
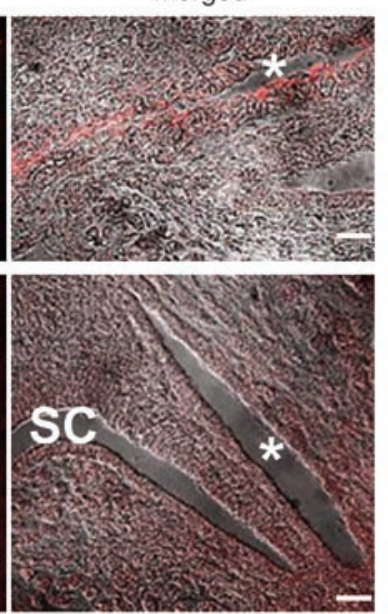

C

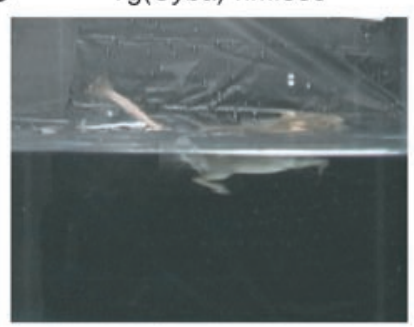

E

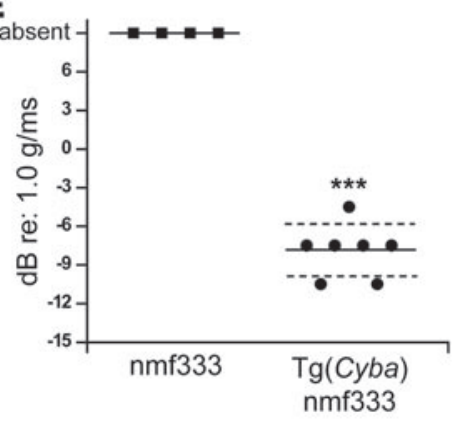

\section{Figure 7}

The Cyba transgene rescues the balance disorder characteristic of the nmf333 strain. (A) Immunostaining of the endolymphatic duct (asterisk) of an embryo from a Cyba-transgenic homozygous nmf333 mouse and from a homozygous nmf333 mouse at E15 using an anti-p22 $2^{\text {phox }}$ antibody. Left: localization of the red immunofluorescence signal (p22 phox). Right: superimposition of the fluorescence signal and the differential interference contrast image (merged). SC, semicircular canal lumen. Scale bars: $20 \mu \mathrm{m}$. (B) Von Kossa staining of calcium salts in the saccule of a Cyba-transgenic homozygous nmf333 mouse (arrow indicates otoconia). $n=3$. Scale bar: $100 \mu \mathrm{m}$. (C) The Cyba transgene restored the ability of nmf333 mice to orient themselves in water as demonstrated by the swimming test. (D) Time spent on fixed-speed rotarod $(10 \mathrm{rpm})$ before falling by WT, homozygous nmf333, and Cyba-transgenic homozygous nmf333 mice during 3 assays over 3 days (d1, d2, d3). The maximum duration of the test was $180 \mathrm{~s}$ (horizontal line; $n=5$ per group). $P<0.0001$ for the genotype variable and $P=0.0042$ for the time variable, 2-way ANOVA; ${ }^{* \star} P<0.01,{ }^{* * \star} P<0.001$, post-hoc Bonferroni test. (E) The Cyba transgene restores the VsEP threshold in mice homozygous for $n m f 333$. Individual VsEP thresholds are shown for $n m f 333 / 333$ (filled squares, $n=4$ ) and Cyba-transgenic homozygous nmf333 (filled circles, $n=7$ ) mice. Mean thresholds are indicated by solid horizontal lines $\pm 1 \mathrm{SD}$ (dashed lines). ${ }^{\star * \star} P<0.0001 ; 1$-tailed $t$ test against the theoretically possible lowest threshold in the nmf333 group (6 dB re $1.0 \mathrm{~g} / \mathrm{ms}$ ). into pseudopregnant foster mothers. The Cyba transgene was constructed by subcloning the mouse $\mathrm{p} 22^{\text {phox }}$-encoding CDNA downstream of the CMV immediate-early enhancer, chicken $\beta$-actin promoter, and chimeric intron that originated from the pTriEx-1.1 vector (Novagen Corp.). The promoterintron-Cyba fragment was then subcloned into a pStec-1 vector that contains an SV40 polyadenylation site downstream of the multiple cloning site. The entire $\mathrm{p} 22^{\text {phox }}$-expression cassette was isolated by restriction digestion followed by gel extraction and used for microinjection. The $n m f 333$ and WT alleles were distinguished based on a novel BslI site introduced into Cyba by the nmf333 point mutation. A 291-bp long piece of genomic DNA was PCR amplified using forward (5'-dCAGATGCCCACTGACTGCTA-3') and reverse (5'-dCGAGCCACAGTACAGCTTCA-3') PCR primers and standard reaction conditions. Following amplification, the reactions were digested directly with BslI (New England BioLabs), and the digestion products were resolved on $2 \%$ agarose gels. The WT allele produces digestion products of 202 and $89 \mathrm{bp}$. The $n m f 333$ allele produces digestion products of 162, 89, and $40 \mathrm{bp}$ (Figure 1C). The presence of the Cyba transgene was detected with PCR using standard reaction conditions and primers that anneal with the chimeric intron $\left(5^{\prime}\right.$-dCTGACTGACCGCGTTACTCC-3') and with the p22phox coding sequence ( $5^{\prime}$-dACCACTGTGTGAAACGTCCA-3'). Experimental procedures were approved by the animal use and care committees of the University of Iowa and The Jackson Laboratory.

Preparation of bone marrow neutrophils. Bone marrow neutrophil granulocytes were used as "neutrophils" in this study, with the exception of the NBT tests that were performed with peripheral blood neutrophils. Bone marrow neutrophil granulocytes were isolated from aseptically removed femur, tibia, and iliac bones of WT, nmf333/nmf333, and Cyba-transgenic mice. Bone marrow cells were flushed from the bones with HBSS containing $1 \%$ glucose and $0.1 \%$ BSA. The cells were pelleted by centrifugation $\left(1,600 \mathrm{~g}\right.$ for $30 \mathrm{~min}$ at $10^{\circ} \mathrm{C}$ ), resuspended in $3 \mathrm{ml}$ of $45 \%$ Percoll (Amersham Pharmacia Biotech), and loaded on a Percoll gradient consisting of $3 \mathrm{ml}$ of $81 \%, 2 \mathrm{ml}$ of $62 \%, 2 \mathrm{ml}$ of $55 \%$, and $2 \mathrm{ml}$ of $50 \%$ Percoll (47). After centrifugation, the cell band between the $81 \%$ and $62 \%$ layers was collected. Contaminating red blood cells were removed by hypotonic shock. The percentage of neutrophils in these cell preparations was greater than $70 \%$ as determined with differential cell counting after Türk staining. 
Western blotting. Bone marrow neutrophils were solubilized in a lysis buffer composed of $100 \mathrm{mM} \mathrm{KCl}, 10 \mathrm{mM} \mathrm{NaCl}, 10 \mathrm{mM}$ HEPES, $1 \mathrm{mM}$ EDTA (pH 7.4), $0.1 \mathrm{mM}$ DTT, $1 \mathrm{mM}$ PMSF, $10 \mu \mathrm{g} / \mathrm{ml}$ chymostatin, and $1 \mu \mathrm{g} / \mathrm{ml}$ protease inhibitor cocktail (Sigma-Aldrich); $1 \%$ Triton X-100; $1 \%$ deoxycholic acid; $1 \%$ NP-40; and $0.05 \%$ SDS. The protein content of cell lysates was resolved by $5-20 \%$ SDS-PAGE and electroblotted onto nitrocellulose membranes. Following a blocking incubation step, 1:1000 dilutions of primary antibodies (polyclonal anti-p22phox [FL-195] from Santa Cruz Biotechnology Inc. or monoclonal anti-actin from Calbiochem Corp.) were added to the membranes for 14 hours. Following multiple washing steps, membranes were incubated with 10,000-fold diluted HRP-conjugated secondary antibody (anti-rabbit IgG or anti-mouse IgM). Immunoblot signals were visualized with an Enhanced Chemiluminescence Detection System (Pierce Biotechnology).

Measurement of ROS. Production of ROS was measured instantaneously with the peroxidase-dependent luminol-amplified chemiluminescence technique, as previously described (18). Briefly, $3 \times 10^{5}$ bone marrow neutrophils were pipetted into the wells of 96 -well plates, and measurements were performed in HBSS supplemented with $1 \mathrm{U} / \mathrm{ml} \mathrm{HRP} \mathrm{and} 250 \mu \mathrm{M}$ luminol. To stimulate Phox activity, the PKC agonist PMA was added at a concentration of $200 \mathrm{ng} / \mathrm{ml}$.

Extracellular superoxide production was measured based on the superoxide dismutase-inhibitable reduction of ferricytochrome $\mathrm{c}(80 \mu \mathrm{M})$ that was monitored at $550 \mathrm{~nm}$ wavelength in the presence or absence of PMA $(200 \mathrm{ng} / \mathrm{ml})$. The rate of superoxide production was calculated based on the initial linear phase of absorbance increase (5-15 minutes after addition of PMA) using an absorption coefficient of $21.1 \mathrm{mM}^{-1} \mathrm{~cm}^{-1}$.

To detect superoxide production by a small number of peripheral blood neutrophils, we used the NBT test as previously described (48). Briefly, mouse tail vein blood was collected on coverslips coated with PMA. After a few minutes, clots were removed and red blood cells were washed off. Coverslips with the attached cells were placed in $1 \mathrm{mg} / \mathrm{ml} \mathrm{NBT}$ solution in HBSS for $60 \mathrm{~min}$. Following fixation with methanol, the cells were counterstained with Safranin O.

B. cepacia lung infection. Mice were infected with B. cepacia (ATCC no. 25609) by intratracheal inoculation with a $25-\mu \mathrm{l}$ bacterial suspension $\left(10^{4}-10^{6}\right.$ CFU in sterile HBSS) under anesthesia. The study was designed to follow changes in body weight. However, the unexpectedly fulminant progression of B. cepacia pneumonia and the sudden death of $n m f 333 / n m f 333$ mice did not allow meaningful weight loss analysis. During the infection experiments, $5 \mathrm{nmf33} / \mathrm{nmf3} 33$ mice were recognized as obviously moribund at 1 of the 2 daily visits and were euthanized: 2 mice in the group infected with $10^{5} \mathrm{CFU}$ were euthanized 3.5 days after inoculation, and 3 mice in the group infected with $10^{4} \mathrm{CFU}$ were euthanized 4 and 4.5 days after inoculation. These 5 mice were not included in the survival curve. For histological analysis, WT and $n m f 333 / n m f 333$ mice were inoculated intratracheally with B. cepacia $\left(10^{4} \mathrm{CFU}\right)$, and infected mice were euthanized 3.5 days later. Lung and spleen were removed under aseptic conditions and weighed; approximately one-half of each organ was homogenized with a glass homogenizer in $1 \%$ saponin solution. Serial dilutions of the homogenate were spread on Luria-Bertani agar plates, and CFU were counted and calculated for the weight of the entire organ. The remaining halves of lung and spleen tissues were used for histology. Tissue samples were fixed in $\mathrm{Zn}$-formalin, paraffin embedded, and sectioned at a width of $5 \mu \mathrm{m}$. Deparaffinized sections were stained with hematoxylin and eosin.

VsEPs. VsEP recordings were based on previously published methods that were modified for the present study (49). Briefly, mice were anesthetized by intraperitoneal injection of xylazine and ketamine. Core body temperature was maintained at $37^{\circ} \mathrm{C}$ using a homeothermic heating blanket system (FHC Inc.). Stimuli were delivered to the head using a volt- age-controlled mechanical shaker. The head was coupled to the shaker platform nonsurgically with a head clip consisting of a lightweight plastic spring hair clip with tines modified to encircle the head anterior to the pinnae. Linear acceleration pulses (17 pulses/s, 2-ms pulse duration) were presented to the cranium in the naso-occipital axis in an alternating manner between normal and inverted polarities. Stimulus amplitude ranged from $+6 \mathrm{~dB}$ to $-18 \mathrm{~dB}$ relative to reference intensity (re) $1.0 \mathrm{~g} / \mathrm{ms}$ (where $1 \mathrm{~g}=9.8 \mathrm{~m} / \mathrm{s}^{2}$ ) adjusted in $3-\mathrm{dB}$ steps. VsEPs were detected with inverting and ground needle electrodes placed posterior to the right pinna and at the ventral neck, respectively. A stainless steel wire was placed subcutaneously at the nuchal crest to serve as the noninverting electrode. Traditional signal averaging was used to resolve responses in electrophysiological recordings. Ongoing electroencephalographic activity was amplified (200,000 times), filtered (300-3,000 Hz, $-6 \mathrm{~dB}$ amplitude points), and digitized ( 1,024 points, $8 \mathrm{~ms} /$ point). For each VsEP response, the 256 waveform multiple primary responses were averaged. All responses were replicated. A bracketing threshold procedure was used wherein recordings began at the maximum stimulus intensity (i.e., $+6 \mathrm{~dB}$ re 1.0 $\mathrm{g} / \mathrm{ms}$ ), with and without acoustic masking, and then the intensity was decreased in $3-\mathrm{dB}$ steps down to $-18 \mathrm{~dB}$. A final recording was conducted at $+6 \mathrm{~dB}$ to confirm the quality of the preparation. A broadband forward masker (50-50,000 Hz, $97 \mathrm{~dB}$ sound pressure level) was presented during VsEP measurements to verify the absence of cochlear responses (49). VsEP threshold, measured in $\mathrm{dB}$ re $(1.0 \mathrm{~g} / \mathrm{ms})$, was determined from the intensity series. Threshold was defined as the stimulus level midway between the level just producing a discernible response and the stimulus level that did not.

Otoconial detection with the von Kossa method and with scanning electron microscopy. Temporal bone samples were fixed with $\mathrm{Zn}$-formalin, paraffin embedded, and sectioned at a width of $5 \mu \mathrm{m}$. To visualize calcium salts with the von Kossa method, deparaffinized samples were incubated in 5\% silver nitrate for 10 minutes, exposed to UV light for 3 minutes, incubated with $5 \%$ sodium thiosulfate for 2 minutes, and counterstained with Nuclear Fast Red (Sigma-Aldrich).

For scanning electron microscopy, paraffin-embedded tissue samples were trimmed to the level of saccule and deparaffinized in xylene. The samples were dehydrated, critical point dried in $\mathrm{CO}_{2}$, sputter-coated with gold palladium, and examined using a Hitachi S4000 scanning electron microscope.

Rotarod test. The balance and motor coordination abilities of WT, homozygous nmf333 and Cyba-transgenic nmf333/nmf333 mice were studied using rotarod tests. Mice were placed onto a cylinder rotating at fixed speed $(10 \mathrm{rpm})$, and latency to fall was measured for a maximum of $180 \mathrm{~s}$. Each mouse was tested in 3 trials over 3 days using a commercial rotarod apparatus (Accuscan Inc.). On the first day, mice were trained in 2 consecutive trials; the third trial was timed and used as a data point for day 1 . Without additional training, the assay was repeated on day 2 and day 3 .

Immunohistochemistry. Temporal bone samples were fixed with Prefer solution (Anatech Ltd.), paraffin embedded, and sectioned at a width of $5 \mu \mathrm{m}$. Sections were deparaffinized and rehydrated. Endogenous peroxidase activity was blocked by incubating samples with $1 \% \mathrm{H}_{2} \mathrm{O}_{2}$ in PBS for 1 hour. Polyclonal rabbit anti-p22 phox antibody (diluted 500-fold) (Santa Cruz Biotech Corp.) and a Tyramine Signal Amplification kit (Invitrogen Corp.) were used according to the manufacturer's instructions to localize p22 phox protein expression. Images were obtained using an LSM-510 confocal microscope (Carl Zeiss Inc.).

Statistics. Data were compared with a log-rank, 2-tailed, unpaired $t$ test or 1- or 2-way ANOVA followed by a post-hoc Tukey's test or Dunnett's test as indicated in the figure legends. Significance from theoretical means was evaluated with a 1 -tailed $t$ test. 


\section{Acknowledgments}

We thank the Neuromutagenesis Facility of The Jackson Laboratory for providing the nmf333 mouse strain; John P. Flaherty, Christopher McCarty, Emma Albee, Sandra Gray, and Leslie Haynes for technical assistance; Joanne Young and Elsie Cough for animal care services; Gregory A. Cox and Kenneth Johnson for critical review of the manuscript; and Gideon Zamba for consultations on statistical analyses. This project was supported by grants from the Carver College of Medicine (to B. Bánfi) and the University of Iowa Center for Gene Therapy for Cystic Fibrosis (NIH P30 DK-54759; John Engelhardt, principal investigator), NIH grant AI 34879-19 (to W.M. Nauseef), NIDCD grant R01 DC006443 (to S.M. Jones), and NIDCD grant R01 DC007431 (to D.E. Bergstrom). The Scientific Services of The Jackson Laboratory are supported in part by a National Cancer Institute Cancer Center Core Grant (CA034196).

Received for publication September 5, 2007, and accepted in revised form December 5, 2007.

Address correspondence to: Botond Bánfi, Inflammation Program, University of Iowa, 2501 Crosspark Road, Coralville, Iowa, USA. Phone: (319) 335-4228; Fax: (319) 335-4194; E-mail: botond-banfi@uiowa.edu.
1. Bedard, K., and Krause, K.H. 2007. The NOX family of ROS-generating NADPH oxidases: physiology and pathophysiology. Physiol. Rev. 87:245-313.

2. Schrenzel, J., et al. 1998. Electron currents generated by the human phagocyte NADPH oxidase. Nature. 392:734-737.

3. Malech, H.L., and Hickstein, D.D. 2007. Genetics, biology and clinical management of myeloid cell primary immune deficiencies: chronic granulomatous disease and leukocyte adhesion deficiency. Curr. Opin. Hematol. 14:29-36.

4. Pollock, J.D., et al. 1995. Mouse model of X-linked chronic granulomatous disease, an inherited defect in phagocyte superoxide production. Nat. Genet. 9:202-209.

5. Jackson, S.H., Gallin, J.I., and Holland, S.M. 1995 The p47phox mouse knock-out model of chronic granulomatous disease. J. Exp. Med. 182:751-758.

6. Lambeth, J.D. 2004. NOX enzymes and the biology of reactive oxygen. Nat. Rev. Immunol. 4:181-189.

7. Geiszt, M., Witta, J., Baffi, J., Lekstrom, K., and Leto, T.L. 2003. Dual oxidases represent novel hydrogen peroxide sources supporting mucosal surface host defense. FASEB J. 17:1502-1504.

8. Moskwa, P., et al. 2007. A novel host defense system of airways is defective in cystic fibrosis. Am. J. Respir. Crit. Care Med. 175:174-183.

9. Moreno, J.C., et al. 2002. Inactivating mutations in the gene for thyroid oxidase 2 (THOX2) and congenital hypothyroidism. N. Engl.J. Med. 347:95-102.

10. Matsuno, K., et al. 2005. Nox1 is involved in angiotensin II-mediated hypertension: a study in Nox1deficient mice. Circulation. 112:2677-2685.

11. Gavazzi, G., et al. 2006. Decreased blood pressure in NOX1-deficient mice. FEBS Lett. 580:497-504.

12. Dikalova, A., et al. 2005. Nox1 overexpression potentiates angiotensin II-induced hypertension and vascular smooth muscle hypertrophy in transgenic mice. Circulation. 112:2668-2676.

13. Paffenholz, R., et al. 2004. Vestibular defects in headtilt mice result from mutations in Nox3, encoding an NADPH oxidase. Genes Dev. 18:486-491.

14. Takeya, R., et al. 2003. Novel human homologues of $\mathrm{p} 47$ phox and $\mathrm{p} 67$ phox participate in activation of superoxide-producing NADPH oxidases. J. Biol. Chem. 278:25234-25246.

15. Banfi, B., Clark, R.A., Steger, K., and Krause, K.H. 2003. Two novel proteins activate superoxide generation by the NADPH oxidase NOX1. J. Biol. Chem. 278:3510-3513.

16. Geiszt, M., Lekstrom, K., Witta, J., and Leto, T.L. 2003. Proteins homologous to p47phox and p67phox support superoxide production by NAD(P)H oxidase 1 in colon epithelial cells. J. Biol. Chem. 278:20006-20012.

17. Cheng, G., Ritsick, D., and Lambeth, J.D. 2004. Nox3 regulation by NOXO1, p47phox, and p67phox. J. Biol. Chem. 279:34250-34255.

18. Banfi, B., et al. 2004. NOX3: a superoxide-generating NADPH oxidase of the inner ear. J. Biol. Chem. 279:46065-46072.

19. Kiss, P.J., et al. 2006. Inactivation of NADPH oxi- dase organizer 1 results in severe imbalance. Curr. Biol. 16:208-213.

20. Ueno, N., Takeya, R., Miyano, K., Kikuchi, H., and Sumimoto, H. 2005. The NADPH oxidase Nox3 constitutively produces superoxide in a 22 phox-dependent manner: its regulation by oxidase organizers and activators. J. Biol. Chem. 280:23328-23339.

21. Nakano, Y., et al. 2007. Critical roles for p22 phox in the structural maturation and subcellular targeting of Nox3. Biochem. J. 403:97-108.

22. Ambasta, R.K., et al. 2004. Direct interaction of the novel Nox proteins with $\mathrm{p} 22$ phox is required for the formation of a functionally active NADPH oxidase. J. Biol. Chem. 279:45935-45941.

23. Kawahara, T., Ritsick, D., Cheng, G., and Lambeth, J.D. 2005. Point mutations in the proline-rich region of 22 phox are dominant inhibitors of Nox1- and Nox2-dependent reactive oxygen generation. J. Biol. Chem. 280:31859-31869.

24. Martyn, K.D., Frederick, L.M., von Loehneysen, K., Dinauer, M.C., and Knaus, U.G. 2006. Functional analysis of Nox 4 reveals unique characteristics compared to other NADPH oxidases. Cell Signal. 18:69-82.

25. Gagnon, L., Bosom, K., Johnson, K., and the Jackson Laboratory Mouse Mutant Resource (Spontaneous). 2006. A new spontaneous mutation on chromosome 17 in the mouse named head slant (bslt). http://www.jax.org/mmr/hslt.html.

26. Robinson, J.M., Badwey, J.A., Karnovsky, M.L., and Karnovsky, M.J. 1985. Release of superoxide and change in morphology by neutrophils in response to phorbol esters: antagonism by inhibitors of calcium-binding proteins. J. Cell Biol. 101:1052-1058.

27. Verbeek, W., et al. 1999. Myeloid transcription factor $\mathrm{C} /$ EBPepsilon is involved in the positive regulation of lactoferrin gene expression in neutrophils. Blood. 94:3141-3150.

28. Bylund, J., Campsall, P.A., Ma, R.C., Conway, B.A., and Speert, D.P. 2005. Burkholderia cenocepacia induces neutrophil necrosis in chronic granulomatous disease. J. Immunol. 174:3562-3569.

29. Hurle, B., et al. 2003. Non-syndromic vestibular disorder with otoconial agenesis in tilted/mergulhador mice caused by mutations in otopetrin 1 . Hum. Mol. Genet. 12:777-789.

30. Thalmann, R., Ignatova, E., Kachar, B., Ornitz, D.M., Thalmann, I. 2001. Development and maintenance of otoconia: biochemical considerations. Ann. N. Y. Acad. Sci. 942:162-178.

31. Björgvinsdóttir, H., Zhen, L., and Dinauer, M.C. 1996. Cloning of murine gp91phox cDNA and functional expression in a human X-linked chronic granulomatous disease cell line. Blood. 87:2005-2010.

32. de Caprona, M.D., Beisel, K.W., Nichols, D.H., and Fritzsch, B. 2004. Partial behavioral compensation is revealed in balance tasked mutant mice lacking otoconia. Brain Res. Bull. 64:289-301.

33. Kislinger, T., et al. 2006. Global survey of organ and organelle protein expression in mouse: combined proteomic and transcriptomic profiling. Cell. 125:173-186.

34. Zhao, X., Yang, H., Yamoah, E.N., and Lundberg,
Y.W. 2007. Gene targeting reveals the role of Oc90 as the essential organizer of the otoconial organic matrix. Dev. Biol. 304:508-524.

35. Hughes, I., Thalmann, I., Thalmann, R., and Ornitz, D.M. 2006. Mixing model systems: using zebrafish and mouse inner ear mutants and other organ systems to unravel the mystery of otoconial development. Brain Res. 1091:58-74.

36. Nakaya, K., et al. 2007. Lack of pendrin HCO3- transport elevates vestibular endolymphatic $[\mathrm{Ca} 2+]$ by inhibition of acid-sensitive TRPV5 and TRPV6 channels. Am. J. Physiol. Renal Physiol. 292:F1314-F1321.

37. Chou, L., Garrels, R.M., and Wallast, R. 1989. Comparative study of the kinetics and mechanisms of dissolution of carbonate minerals. Chem. Geol. 78:269-282.

38. DeCoursey, T.E., Morgan, D., and Cherny, V.V. 2003. The voltage dependence of NADPH oxidase reveals why phagocytes need proton channels. Nature. 422:531-534.

39. Banfi, B., et al. 1999. A novel $\mathrm{H}(+)$ conductance in eosinophils: unique characteristics and absence in chronic granulomatous disease. J. Exp. Med. 190:183-194

40. Geiszt, M., Kapus, A., Német, K., Farkas, L., and Ligeti, E. 1997. Regulation of capacitative Ca2+ influx in human neutrophil granulocytes. Alterations in chronic granulomatous disease. J. Biol. Chem. 272:26471-26478.

41. Szászi, K., Sirokmány, G., Di Ciano-Oliveira, C., Rotstein, O.D., and Kapus, A. 2005. Depolarization induces Rho-Rho kinase-mediated myosin light chain phosphorylation in kidney tubular cells. Am. J. Physiol. Cell Physiol. 289:C673-C685.

42. Segal, A.W., Geisow, M., Garcia, R., Harper, A., and Miller, R. 1981. The respiratory burst of phagocytic cells is associated with a rise in vacuolar $\mathrm{pH}$. Nature. 290:406-409.

43. Grimnes, S., and Martinsen, O.G. 2000. Bioimpedance and bioelectricity basics. Academic Press. San Diego, California, USA. 359 pp.

44. Lang, F., Vallon, V., Knipper, M., and Wangemann, P. 2007. Functional significance of channels and transporters expressed in the inner ear and kidney. Am. J. Physiol. Cell Physiol. 293:C1187-C1208.

45. Everett, L.A., et al. 2001. Targeted disruption of mouse Pds provides insight about the inner-ear defects encountered in Pendred syndrome. Hum. Mol. Genet. 10:153-161.

46. Royaux, I.E., et al. 2003. Localization and functional studies of pendrin in the mouse inner ear provide insight about the etiology of deafness in Pendred syndrome. J. Assoc. Res. Otolaryngol. 4:394-404.

47. Abdel-Latif, D., et al. 2004. Rac2 is critical for neutrophil primary granule exocytosis. Blood. 104:832-839.

48. Francke, U., Ochs, H.D., Darras, B.T., and Swaroop, A. 1990. Origin of mutations in two families with $\mathrm{X}$-linked chronic granulomatous disease. Blood. 76:602-606.

49. Jones, T.A., and Jones, S.M. 1999. Short latency compound action potentials from mammalian gravity receptor organs. Hear. Res. 136:75-85. 